\title{
ANÁLISE DAS ESTRATÉGIAS DESEMPENHADAS PELO SETOR SUPERMERCADISTA NO BRASIL PARA A VENDA DE FLV ORGÂNICOS
}

\author{
Analysis of the strategies employed by the \\ retail branch in Brazil to the selling of organics \\ fruits and vegetables
}

Eduardo João Moro*

\section{Resumo}

O consumo de alimentos orgânicos tem apresentado um grande crescimento, sobretudo, a partir da década de 1990. Atualmente o mercado mundial movimenta US\$ 40 bilhões, 39\% a mais que em 2003. Embora a Europa e os Estados Unidos se destaquem na produção e comercialização, outros países, como o Brasil, começam também a despontar no cenário internacional. O mercado nacional movimenta cerca de $\mathrm{R} \$ 300$ milhões, com taxas de crescimento de 30\% ao ano. Percebendo o potencial desse mercado, os supermercados surgem como grande canal de distribuição e apresentam os alimentos orgânicos através de significativos esforços mercadológicos a fim de alavancar as vendas. Diante disso, propõe-se uma metodologia de análise desses esforços que possibilite organizar dados coletados no campo de pesquisa, através de critérios trazidos do marketing, e a posterior análise dos mesmos através de uma classificação que procura levar em conta, fundamentalmente, a realidade do mercado varejista brasileiro e suas especificidades.

Palavras-chave: Alimentos orgânicos. Consumo. Supermercados. Estratégias de venda.

* Mestrando do Programa de Pós - graduação em Sociologia Política pela Universidade Federal de Santa Catarina. Email: edujoaomoro@yahoo.com.br 


\section{Abstract}

The consumption of organic food has shown a large growth, specially, after the 1990's. Currently the world market moves US\$ 40 billion, 39\% more than in 2003. Althought Europe and USA higlihths in production and trade, other countries, such as Brazil, also start to emerge in the internacional scenery. The internal market generates about $R \$ 300$ million, with growing rates of 30 per cent-a-year. Noticing the potencial of this commerce, the supermarkets raise as a big organic distribution channel, and present organic food through meaningful market efforts to propel even more sales. The objective of this article is proposed, proposed a methodology that allows the data collected in the field research, through criteria used by other areas of knowledge, such as marketing, and the further analysis of this data through a classification that seeks to take into consideration, fundamentally, the reality of the brazilian retail market and it's specificities.

Keywords: Organic food. Consumption. Supermarkets. Sales strategies

\section{INTRODUÇÃO}

A venda de alimentos e bebidas orgânicas alcançou aproximadamente US\$ 40 bilhões em 2006, tendo um crescimento de um pouco mais de $39 \%$ se comparado aos valores fornecidos em 2003 pela mesma fonte (WILLER E YUSSEFI, 2007). Embora a Europa e os Estados Unidos se destaquem na produção e comercialização, a primeira movimentando US\$ 13,7 bilhões e o segundo US\$ 13 bilhões em 2004 (WILLER E YUSSEFI, 2005), outros países, como o Brasil, Argentina e Austrália, começam também a despontar no cenário internacional. O Brasil, segundo matéria da revista ISTO É DINHEIRO (ARAÚJO, 2005), possui 19 mil fazendas que produzem cerca de 300 mil toneladas e movimentam um mercado de R\$ 300 milhões ao ano. Segundo o Instituto Biodinâmico (IBD, 2007), o País surge como o segundo maior em hectares cultivados organicamente devido a inserção de 5,7 milhões de hectares de vegetação nativa que proporcionam o extrativismo sustentável de castanha, açaí, pupunha, látex, frutas e outras espécies das matas tropicais, principalmente da Amazônia. 
Esse quadro favorável gerou interesse dos supermercados, que em pouco tempo se tornaram o principal canal de distribuição de orgânicos no Brasil e no mundo. Nos Estados Unidos, por exemplo, em 2005, 73\% dos supermercados ofereciam produtos orgânicos aos consumidores, conforme dados do Departamento de Agricultura do país (U.S. DEPARTMENT OF AGRICULTURE, 2006). Já na Europa, segundo a empresa de consultoria Organic Monitor (2007), 48\% das frutas, legumes e verduras orgânicas foram distribuídas em supermercados. A grande demanda nos países europeus e nos Estados Unidos impulsionaram a abertura de supermercados exclusivamente orgânicos, como no caso da Alemanha, por exemplo, onde no primeiro semestre de 2004 foram abertas 11 lojas de produtos orgânicos.

No Brasil os supermercados também vêm desempenhando um papel importante como principal canal de distribuição, deixando para trás as feiras, as entregas a domicílio e outros canais de venda. Segundo pesquisa realizada pela Folha de São Paulo (25 de maio de 2004, p. B4), o número de feiras tem diminuído no Estado de São Paulo. Em 1994, quando a população era de 9,86 milhões de habitantes, havia 904 feiras; em 2004, com 10,68 milhões, 905 feiras. Já os supermercados, no mesmo período, cresceram de 586 mil para 799 mil.

Segundo a Revista Exame (15 de janeiro de 2003), apesar de no País não haver uma Whole Foods (a rede de supermercados orgânicos que faturou US\$ 4,51 bilhões de dólares em 2005), "grandes varejistas, como Pão de Açúcar e Carrefour, vem ampliando a oferta desses produtos. As grandes redes varejistas começaram a perceber o potencial desse mercado há cerca de cinco anos, quando foram procurados por produtores orgânicos”. Além de São Paulo e Rio de Janeiro, outras capitais também se destacam, como o caso Florianópolis, cujos orgânicos podem ser encontrados facilmente nas principais redes de supermercados, passando recentemente a serem vendidos também em alguns mercados com menor porte (MORO, 2007). Mais do que a simples oferta de orgânicos, muitas redes de supermercados têm se destacado por adotarem importantes estratégias de vendas a fim de atrair os consumidores. Contudo, as ações dos supermercados ainda é um assunto muito pouco explorado no País, sobretudo pela Sociologia, desconsiderando o papel fundamental que estes possuem nas mudanças 
dos hábitos alimentares das pessoas, bem como de influência na formação ou escolha dos "estilos de vida" dos indivíduos. Pensando nisso, buscase, através de ferramentas de apoio trazidas do marketing, somado a um diálogo com autores da Sociologia, propor uma metodologia de análise das estratégias desempenhadas pelos supermercados na venda de FLV (frutas, legumes e verduras) orgânicos que seja condizente com a realidade nacional e aplicável em diferentes regiões do país, vindo a contribuir com um tema ainda muito carente de publicações.

$\mathrm{O}$ artigo se divide em três partes: na primeira são apresentadas as idéias que serviram de base na elaboração da análise das estratégias; na segunda tais idéias são discutidas e aplicadas; e na terceira apresentase como resultado um critério que se acredita ser capaz de analisar as diferentes estratégias assumidas pelo setor supermercadista na venda de FLV orgânicos.

\section{IDÉIAS FUNDANTES}

\section{Marketing}

A idéia de analisar as estratégias dos supermercados na venda de FLV orgânicos recebe, inicialmente, contribuições oriundas do marketing, mais especificamente do denominado "marketing mix". Porém, antes de adentrar nesse ponto faz-se necessário trazer alguns conceitos básicos.

Um destes é o próprio conceito de "marketing", havendo, segundo Kotler (1980), inúmeras conceituações, embora na sua opinião todas elas ofereçam apenas perspectivas parciais. Segundo o autor, o "marketing" é um conjunto de técnicas que tem por objetivo aprimorar o processo de troca e melhorar o desempenho da organização em termos de resultado, através da satisfação das necessidades e desejos das pessoas envolvidas no processo de troca. Rocha e Christensen (1987, p. 21) também apresentam o caráter controverso do termo, afirmando não haver nenhuma definição "totalmente consagrada, não se tendo chegado a um consenso". Os autores trazem outras definições importantes, como de Peter Drucker, que trata o marketing como um "processo do qual a economia é integrada à sociedade para servir as necessidades humanas", e Theodore Levitt, que trata como 
o "processo de atrair e manter o cliente". Pode-se observar, portanto, a variação de perspectivas em torno do marketing, evidenciando a visão de processo social de Drucker, passando pela visão de um processo de troca de Levitt e como um instrumento gerencial sob o ponto de vista de Kotler (ROCHA E CHRISTENSEN, 1987, p. 21).

Já o denominado "marketing mix", ou “composto de marketing”, foi utilizado como uma importante ferramenta para compor a análise das estratégias dos supermercados, dialogando constantemente com a "classificação das estratégias dos supermercados", que será vista mais à frente. Segundo Rocha e Christensen (1987, p. 37), o "marketing mix" é o "conjunto de instrumentos controláveis pelo gerente de marketing, através dos quais ele pode obter melhor ajustamento entre a oferta que sua empresa faz ao mercado e a demanda existente”. Kotler (1980) restringese a conceituá-lo como "o conjunto de variáveis controláveis que a empresa pode utilizar para influenciar as respostas dos consumidores”. No início da década de 60, Jerome McCarthy apresentou o conceito que ficou conhecido como os 4 Ps (product, price, place e promotion). Segundo o autor, através dessas quatro ferramentas - produto, preço, ponto de venda e promoção - poder-se-ia chegar ao consumidor desejado.

Vale ressaltar que com o passar dos anos alguns autores desenvolveram os 4 Ps, chegando até 7 Ps. Dos quatro Ps já existentes adicionou-se a Physical Evidence (Evidências Físicas), visando abarcar serviços intangíveis; Process (Processo), referindo-se às diferentes formas de uma empresa fazer negócios; e People (Pessoas), destacado principalmente no marketing de serviço, uma vez que estes são também intangíveis e os clientes buscam outro tipo de informações para avaliar a qualidade e o valor do serviço.

Levando em conta tratar-se de uma análise de produtos (e não serviços) e que o mix é composto por inúmeras atividades, conforme afirma Kotler, sendo os "quatro Ps" o critério mais conhecido, difundido e utilizado, serão as atividades contidas nele as utilizadas como orientador do presente artigo. Lembrando ainda que o artigo não pretende promover uma discussão a respeito da quantidade de Ps existentes na literatura, nem questionar as diversas colocações, mas apenas utilizá-los como ferramenta na construção de um modelo de análise. 
Antes de adentrar na parte da aplicação dos 4 Ps, porém, surge ainda a presença do que se considera o "Novo Marketing Mix", criado por Lauterborn. Para ele, mais importante que um produto ou serviço para ofertar é ter cliente para satisfazer, e, para tanto, é necessário proporcionar conveniências para torná-lo fiel. Portanto, segundo Lauterborn, do ponto de vista do consumidor, cada ferramenta de marketing visa oferecer benefício ao cliente (grifo meu). Este autor afirma ainda que as empresas devem observar os 4 Ps em termos dos 4 Cs do consumidor. Portanto, observando o produto sob a ótica do consumidor tem-se os 4 Cs: Consumers needs and wants: necessidades e desejos do cliente; Cost to the Consumer: custo para o consumidor; Convenience: conveniência; e Communication: comunicação.

Os 4 Cs não surgem em oposição aos 4 Ps, mas, ao contrário, complementando-os, oferecendo uma nova perspectiva, desta vez vinda do consumidor. Nesse artigo, da mesma forma, ambos os critérios dialogam, oferecendo um número maior de ferramentas para a análise pretendida. Maiores detalhes a respeito do "Novo Marketing Mix", bem como sua aplicação serão vistos adiante.

\section{Eestratégias dos supermercados na venda de alimentos orgânicos - mínima, básica e máxima}

Outras contribuições no intuito de analisar as estratégias dos supermercados na venda de FLV orgânicos são trazidas por Richter et al. (2001 apud GUIVANT, 2003) e Guivant (2004). Richter et al. (2001) identificam três estratégias de venda a partir de pesquisas realizadas em supermercados dos Estados Unidos e da Europa Ocidental no ano de 2000. A primeira - denominada estratégia "mínima" - é encontrada em supermercados cuja quantidade de produtos orgânicos é limitada, não havendo anúncios destes produtos separadamente e não sendo visualmente dominantes na loja. Mais do que isso, a empresa não possui marca própria de produtos orgânicos nem apresenta um perfil orgânico ou ambientalista. A segunda estratégia - "básica" - envolve uma quantidade maior de produtos naturais e/ou orgânicos, havendo comunicação por parte da empresa ressaltando seu compromisso com tais produtos. Contudo, a seleção dos produtos se dá somente através de critérios de lucro, sem nenhum tipo de subsídio. Por 
fim, a terceira estratégia, denominada “máxima”, enquadra-se em empresas em que há maior valorização dos produtos naturais e orgânicos, somado ao apoio aos produtores, com intuito de manter ou aumentar a oferta, e ao treinamento dos funcionários a fim de orientar os consumidores a respeito dos benefícios do consumo de tais produtos, bem como para mantê-los em bom estado na gôndola.

Guivant (2004), por sua vez, reelabora as estratégias descritas por Richter et al., pois acredita serem limitadas quando se analisam os supermercados no Brasil, ficando muitos deles concentrados em uma mesma classificação, homogeneizando práticas que são diferentes e difusas quando vistas mais profundamente. A autora, dentre outras modificações, subdivide as estratégias em fraca e forte, apresentando-as da seguinte maneira:

- estratégia mínima fraca: menos de 50 produtos, compostos principalmente por produtos secos;

- estratégia mínima forte: menos de 50, porém com a presença de produtos frescos;

- $\quad$ estratégia básica fraca: de 50 a 200 produtos orgânicos, principalmente produtos secos;

- estratégia básica forte: de 50 a 200 produtos, incluindo produtos frescos;

- estratégia Máxima Fraca: refere-se à supermercados que oferecem até 400 artigos orgânicos, predominantemente frescos, e com exposição de destaque em refrigeradores. Mais do que isso há uma preocupação do supermercado com a qualidade e com a certificação dos produtos, além de uma clara separação entre orgânicos, convencionais e hidropônicos, com alguma sinalização referente ao tipo de produto. Nenhuma publicidade especial em torno dos orgânicos e as negociações ocorrendo diretamente com os produtores.

- estratégia Máxima Forte: compromisso especial com os orgânicos, além de uma equipe treinada, motivada e educada, somada às outras características da "estratégia máxima fraca”. 


\section{Construção do modelo de análise}

Tendo como base as idéias apresentadas nos itens 1.1 e 1.2 parte-se agora para a elaboração de um método de análise das estratégias dos supermercados na venda de FLV orgânicos. Conforme já explanado, esse processo se dá analisando separadamente cada "P" do marketing mix em diálogo com as estratégias trazidas por Richter et al. e Guivant.

\section{Produto}

Segundo Kotler (1980, p. 224), um produto é qualquer coisa que pode ser oferecido a um mercado para a aquisição ou consumo; inclui objetos físicos, serviços, personalidades, lugares, organizações e idéias. Indo ao encontro da proposta do artigo consideram-se produtos os FLV orgânicos dispostos no ponto de venda (setor de hortifruti). Portanto, o primeiro $\mathrm{P}$ do composto mercadológico a ser trazido corresponde aos "FLV orgânicos" como um todo.

O caráter do produto é encarado de maneira distinta entre 0 consumidor e a empresa que produz ou fornece. O produto tangível, conforme afirma Kotler (1980, p. 22), trata-se do objeto físico, como por exemplo, um pacote de $200 \mathrm{~g}$ de alface americana orgânica da marca $\mathrm{X}$. Já o produto genérico, conforme o mesmo autor, refere-se à utilidade ou benefício que está sendo oferecido ou procurado pelo comprador. Em outras palavras, a pessoa que compra a alface americana orgânica pode não estar comprando somente uma verdura sem agrotóxicos, mas segurança, saúde, longevidade, etc. Neste caso, porém, o enfoque se dá no produto tangível, em seu aspecto, estilo, embalagem, quantidade, etc.

$\mathrm{Na}$ análise do produto tangível são observados dois aspectos:

1. Variedade de itens;

2. Variedade de marcas.

A importância de se vislumbrar estes aspectos está destacada no próprio conceito de "supermercado". Segundo Lewison e Delozier (1982 apud CHAVEZ, 2002, p. 51), supermercados são lojas de autoserviço no varejo de alimentos. Os produtos oferecidos pelo 
supermercado incluem uma ampla variedade, como: mercearia, carnes frescas, hortifrutículas, frios e laticínios, etc. Outra conceituação é a de Silveira e Lepsch (1997, apud CHAVEZ, 2002, p.51), que apresentam os supermercados como "um varejo generalista, que revende para o consumidor uma ampla quantidade de produtos, dispostos de forma departamentalizada, no sistema de autoserviço". Observa-se em ambas conceituações a importância de se observar a quantidade de produtos e, conseqüentemente, de marcas ofertadas, tendo em vista a estrutura e o papel do supermercado como distribuidor de uma ampla variedade de produtos. Apenas como ilustração, em casos de grandes lojas, com tamanho variando entre 2.001 a 5.000 mil metros quadrados, há uma oferta média de pouco mais de 16 mil e 200 itens, e, em lojas com área de venda superior a 5 mil metros quadrados, pode-se encontrar mais de 35 mil itens (ABRAS, 2007).

Para se obter os dados referentes à quantidade de itens e marcas de orgânicos em um determinado supermercado optou-se pela coleta das informações na própria gôndola, contrariando muitos autores que consideram em suas classificações o número do estoque ou do cadastro de produtos. Antes de avançar, vale ressaltar o porquê de tal escolha. Segundo Silva (2003, p. 38), um supermercado por ela pesquisado, aqui denominado como supermercado A, possuía na época 700 produtos orgânicos cadastrados; enquanto que outro supermercado, aqui B, contava com 543 produtos orgânicos na lista. Entretanto, segundo a mesma autora, dos 543 produtos orgânicos cadastrados pelo supermercado B, 319 eram do setor hortifruti e somente 108 estavam presentes na oferta semanal. Da mesma forma o supermercado A, cujo cadastro possuía 700 produtos, 249 do setor hortifruti, apenas 111 estavam presentes na oferta da semana. Esse exemplo mostra que o número de cadastro ou estoque pode esconder informações importantes devido à dificuldade do pesquisador na conferência dos dados. Além disso, quando se trata de redes com mais de um supermercado torna-se difícil saber como se dá a divisão dos produtos cadastrados dentre as lojas da rede. Portanto, um grande número de produtos e marcas cadastradas ou no estoque não representa, necessariamente, acesso por parte dos consumidores. 
Outra questão que pode gerar enganos são as informações obtidas do próprio supermercado. Muitas vezes há discrepâncias entre as informações fornecidas pelos responsáveis do setor e a realidade na gôndola. Como exemplo pode-se citar um supermercado pesquisado em Florianópolis-SC, denominado aqui de supermercado $C$, que, segundo o chefe do departamento, possuía 35 a 40 itens dispostos nas gôndolas, de 5 marcas diferentes, quando na realidade encontraram-se apenas 24 itens de 2 marcas; e outro, denominado supermercado D, cujo responsável afirmou haver 30 itens, enquanto foram observados 24. Portanto, devido às limitações e possíveis falhas que possam vir a ocorrer na análise de estoque ou cadastro, bem como em entrevistas com funcionários, faz-se necessária a conferência direta na gôndola, ou seja, assumindo a perspectiva de um consumidor.

Conforme foi dito acima, concomitantemente com a análise baseada nos 4 Ps trazidos do marketing, serão utilizadas as classificações das estratégias dos supermercados trazidas por Richter et al. e Guivant. Porém, devido às modificações sugeridas, as estratégias propostas por tais autores sofrem também modificações, partindo da alteração dos itens de estoque para os itens de ponto de venda e devido à inclusão do item "variedade de marcas”. Portanto, a classificação das estratégias apresenta-se da seguinte maneira:

- estratégia mínima fraca: menos de 30 itens FLV orgânicos no setor hortifruti, com até $\mathbf{5}$ marcas diferentes (grifo meu), compostos principalmente por produtos secos;

- estratégia mínima forte: menos de 30 itens FLV orgânicos no setor hortifruti, com até 5 marcas diferentes (grifo meu), porém com a presença de produtos frescos;

- estratégia básica fraca: de 31 a 50 itens FLV orgânicos no setor hortifruti, com 6 a 10 marcas de orgânicos diferentes (grifo meu), principalmente compostos por produtos secos;

- estratégia básica forte: de 31 a 50 itens FLV orgânicos no setor hortifruti, com 6 a 10 marcas diferentes (grifo meu), incluindo produtos frescos; 
- estratégia Máxima Fraca: refere-se à supermercados que oferecem mais de 51 itens orgânicos refrigerados no setor hortifruti, com mais de 10 marcas diferentes (grifo meu), predominantemente frescos e com exposição de destaque em refrigeradores. Mais do que isso há uma preocupação do mercado com a qualidade e com a certificação dos produtos, além de uma clara separação entre orgânicos, convencionais e hidropônicos, com alguma sinalização referente ao tipo de produto;

- estratégia Máxima Forte: compromisso especial com os orgânicos, além de uma equipe treinada, motivada e educada, somada às outras características da "estratégia máxima fraca”.

\section{Preço}

Segundo Dunne (2001, p. 332), existem seis tipos básicos de varejistas que utilizam o formato baseado em loja: lojas de departamento, loja de especialidades, supercentros, especialistas por categorias, lojas de conveniência e, o mais importante para o artigo, os supermercados. Segundo o autor, os supermercados caracterizam-se como "varejistas que vendem itens de mercearia e alguns produtos de caráter geral através de instalações físicas em grande escala, com expositores para autoserviço e autoseleção que possibilita ao varejista transferir o desempenho de algumas funções de marketing ao consumidor". O conceito apresentado remete a princípios que visam melhorar a produtividade do varejo e reduzir custos de distribuição. São eles: exibidores para autoserviço e autoseleção, centralização dos serviços ao cliente no caixa, instalação física de grande escala e baixo custo, amplo sortimento de mercadorias para facilitar compra de múltiplos itens e forte ênfase em preço. Segundo Urbany (2001, p. 428), o "preço é alguma unidade de valor entregue por uma parte em troca de alguma coisa recebida de outra parte", neste caso, o preço refere-se ao valor pago pelo consumidor, independente da forma de pagamento, em troca de um FLV orgânico.

Apesar da nítida relação entre os supermercados e a ênfase no preço, a classificação proposta não avança nesse ponto, tendo em vista a variação desse fator de uma região para outra. Torna-se, portanto, muito 
difícil criar um padrão geral sem considerar as especificidades de cada região, como a distância percorrida pelos produtos até chegarem aos supermercados, bem como padrões de concorrência que são específicos de cada uma. Além disso, muitas vezes o preço não pode ser controlado pelo supermercado, tendo em vista que fatores climáticos e econômicos fazem com que haja variações que fogem da responsabilidade dos mesmos.

\section{Propaganda}

Segundo Shimp (2002, p. 364), atualmente os consumidores não possuem muito tempo e não percorrem mais lentamente os corredores examinando os produtos expostos, elevando com isso a importância da comunicação de marketing. Diante disso, o autor coloca a publicidade eficaz e outras formas de comunicação de marketing como "absolutamente cruciais para criação da consciência da marca (...) e para tirar os produtos dos depósitos dos distribuidores e das prateleiras das lojas”.

Acredita-se que a comunicação desempenhada pelos supermercados no caso dos FLV orgânicos possui especificidades, sobretudo pela ênfase da concorrência não ocorrer entre as marcas, mas entre os tipos de produtos. Em outras palavras, os orgânicos passaram a disputar seu espaço no varejo recentemente, estando ainda em período de maturação no mercado, concorrendo muito mais com FLV prontos para o consumo, higienizados, hidropônicos e os próprios convencionais do que as marcas de orgânicos entre si. Portanto, o foco da análise recai muito mais na comunicação dos supermercados com relação aos produtos orgânicos do que em uma disputa entre marcas.

Para facilitar a elucidação das análises e limitar as ações selecionadas para as mesmas, faz-se necessário trazer a tona alguns conceitos importantes presentes na "promoção", o terceiro P do "marketing mix".

Atualmente uma empresa não pode se restringir a desenvolver um bom produto e ter um bom preço; mais do que isso deve ter um eficiente programa de comunicação e promoção, pois, segundo Kotler (1980, p. 380), "toda empresa é forçada, pela própria natureza dos clientes e da concorrência, a adotar o papel de comunicador". Segundo Rocha e Christensen (1987, p. 169), essas comunicações de marketing 
se realizam através dos instrumentos do composto promocional, a fim de manter vínculos entre o fabricante e o consumidor, ou, como afirma Kotler (1980, p.396), a empresa busca um relacionamento "emocionalmente satisfatório" com seus clientes, ou seja, um relacionamento duradouro e não mais fundamentado em vendas "eventuais". Este composto promocional trata-se de:

(...) conjunto dos instrumentos de marketing voltados para informar o cliente atual ou potencial sobre as ofertas da empresa, motivá-lo a considerar essas ofertas como alternativas de compra e persuadi-lo a adquirir os produtos ou serviços da empresa como melhor alternativa para a realização de seus desejos ou o atendimento de suas necessidades (KOTLER, 1980, p.396),

É possível encontrar diferenças entre os autores com o passar dos anos na descrição dessas ferramentas ou instrumentos de propaganda. No presente artigo foram utilizadas as idéias trazidas por Shimp (2002, p. 364), que caracteriza os instrumentos ou as ferramentas de marketing da seguinte forma:

- Venda pessoal: “comunicação de pessoa a pessoa na qual um vendedor informa e educa possíveis clientes procurando influenciar suas opções de compra”.

- Publicidade ou propaganda: “comunicação não-pessoal paga por um patrocinador identificado e envolve comunicação de massa via jornais, revistas, rádio, televisão e outros veículos (p.ex., cartazes, placas em pontos de ônibus), ou comunicação direta ao consumidor via mala-direta”.

- Relações públicas: "usa a comunicação não-pessoal a uma audiência de massa, assim como a publicidade, porém o espaço não é pago diretamente pela empresa que dele desfruta".

- Promoção de vendas: "consiste todas as atividades de marketing que procure estimular ações rápidas dos compradores ou, em 
outras palavras, procuram mover vendas imediatas de um produto (daí o nome promoção de vendas)".

- Marketing de patrocínio: "é a prática de promover os interesses de uma empresa e suas marcas associando-a a um evento específico (p.ex., um campeonato ou a uma causa caritativa (p.ex.; a Cruz Vermelha))."

- Comunicação de ponto de venda: "inclui toda sinalização displays, posters, quadros, cartões e uma variedade de outros materiais visuais - que é concebida para influenciar decisões de compra no ponto de venda”.

Os supermercados são lojas de autoserviço, ou seja, não possuem, comumente, a presença de vendedores exercendo a venda pessoal no setor hortifruti, exceto nos casos onde a balança se localiza no setor, o que é cada vez mais incomum. A maior parte das ferramentas descritas extrapolam os limites do ponto de venda - nesse caso o setor hortifruti - como a publicidade e propaganda e relações públicas, que geralmente utilizam meios de comunicação de massa, e o marketing de patrocínio, que, da mesma forma, está ligada à associações que se dão fora do ponto venda. A exceção é a comunicação de ponto de venda e a promoção de vendas, que foram colocadas em análise. A primeira, conforme o próprio nome aponta, está ligada ao ponto de venda, enquanto que a promoção de vendas, especificamente as orientadas para o consumidor, podem estar dispostas no local onde estão os produtos. Com a inserção da "propaganda", a análise passa a abarcar:

- estratégia mínima fraca: menos de 30 itens FLV orgânicos no setor hortifruti, com até 5 marcas diferentes, compostos principalmente por produtos secos e sem nenhuma ação de comunicação no ponto de venda (grifo meu);

- estratégia mínima forte: menos de 30 itens FLV orgânicos no setor hortifruti, com até 5 marcas diferentes, porém com a presença de produtos frescos e sem nenhuma ação de comunicação no ponto de venda (grifo meu); 
- estratégia básica fraca: de 31 a 50 itens FLV orgânicos no setor hortifruti, com 6 a 10 marcas de orgânicos diferentes, principalmente compostos por produtos secos, com ações a fim de atrair a atenção para os produtos com intuito de ativar as vendas (grifo meu);

- estratégia básica forte: de 31 a 50 itens FLV no setor hortifruti, com 6 a 10 marcas diferentes, incluindo produtos frescos, com ações a fim de atrair a atenção para os produtos com intuito de ativar as vendas (grifo meu);

- estratégia Máxima Fraca: refere-se a supermercados que oferecem mais de 51 itens refrigerados no setor hortifruti, com mais de 10 marcas diferentes, predominantemente frescos e com exposição de destaque em refrigeradores. Mais do que isso há uma preocupação do mercado com a qualidade e com a certificação dos produtos, além de ações permanentes de comunicação no ponto de venda, que departamentalizem a área dentro do setor, promovendo as vendas e facilitando o acesso por parte dos consumidores (grifo meu);

- estratégia Máxima Forte: compromisso especial com os orgânicos, além de uma equipe treinada, motivada e educada, somada às outras características da "estratégia máxima fraca".

\section{Ponto de venda}

Segundo Dunne (2002, p. 342), a loja é uma parte importante daquilo que se oferece ao cliente, ou seja, a loja precisa ajudar o varejista a atrair o consumidor para dentro e torná-lo cliente leal. Para tanto, os varejistas devem se preocupar em como o consumidor se sente no interior da loja, tendo ele maior probabilidade de "fazer compras maiores e mais freqüentes se o ambiente total da loja for confortável e acolhedor e os encoraja a dar uma olhada nos produtos expostos".

Foi visto anteriormente que o "ponto de venda" faz parte de um dos Ps do composto de marketing, contudo, segundo Dunne (2002), para 
criar uma imagem positiva a loja depende do que denomina "composto de varejo". Esse composto aproxima-se bastante do "composto de marketing" utilizado no artigo - 4 Ps -, embora o segundo seja mais indicado no caso do varejo (ARAÚJO, 2008). De fato, o "composto de varejo" dentro da metodologia de pesquisa utilizada mostrou-se útil, sobretudo no item denominado "atributos físicos".

Segundo Dunne (2002, p. 342), o “composto de varejo” é a combinação de mercadoria, preços, publicidade, localização, atendimento ao cliente, vendas, distribuição física e o projeto do prédio. Já Araújo (2008) traz em sua descrição o composto de varejo como um conjunto de inúmeras variáveis, como local, mercadoria, comunicação, preço, serviços, atributos físicos e pessoa. Ainda segundo Araújo (2008), os atributos físicos compreendem aspectos externos e internos da loja. No primeiro caso relaciona-se com a comunicação feita fora da loja, como sinalização de fachada, estacionamento, facilidade de acesso, etc., enquanto o segundo refere-se a aspectos internos, como salão da loja, layout, sinalização, departamentalização e identidade visual. Indo de encontro ao recorte proposto nos 4 Ps, foi descartada a análise dos aspectos externos, levando em consideração itens presente nas gôndolas abastecidas com FLV orgânicos nos supermercados.

Para facilitar a coleta dos dados dividiu-se a análise em 4 tópicos:

- Acesso ao ponto de venda: nesse item será analisado como se dá o acesso do consumidor até o local onde os orgânicos estão sendo oferecidos, a partir do momento em que ele visualiza o setor hortifruti até a gôndola de orgânicos.

- Separação dos FLV orgânicos no ponto de venda: analisa como se dá a utilização do espaço descrito acima, ou seja, se o espaço é realmente abastecido apenas com FLV orgânicos;

- Condições dos alimentos: são verificados eventuais problemas com os alimentos orgânicos no ponto de venda;

- Outras observações: traz dados considerados relevantes relacionados à iluminação, ausência de etiquetas de preço, etc. 
Por fim, as estratégias de Richter et al. (2001 apud GUIVANT, 2003) e reelaboradas por Guivant (2004) são revistas no último ponto analisado. Da mesma forma que nos demais itens foram propostas modificações que reconfiguraram as estratégias da seguinte maneira:

- estratégia mínima fraca: menos de 30 itens FLV orgânicos no setor hortifruti, com até 5 marcas diferentes, sem nenhuma ação de comunicação no ponto de venda e colocados em espaços juntamente com os demais de FLV (grifo meu), compostos principalmente por produtos secos;

- estratégia mínima forte: menos de 30 itens FLV orgânicos no setor hortifruti, com até 5 marcas diferentes, porém com a presença de produtos frescos refrigerados, sem nenhuma ação de comunicação no ponto de venda e colocados em gôndolas juntamente com os demais tipos de FLV (grifo meu), porém com a presença de produtos frescos;

- estratégia básica fraca: de 31 a 50 itens FLV no setor hortifruti, com 6 a 10 marcas de orgânicos diferentes, principalmente compostos por produtos secos, com ações a fim de atrair a atenção para os produtos com intuito de ativar as vendas, colocados em espaços separados dos convencionais (grifo meu), principalmente compostos por produtos secos;

- estratégia básica forte: de 31 a 50 itens FLV no setor hortifruti, com 6 a 10 marcas diferentes, incluindo produtos frescos refrigerados, com ações a fim de atrair a atenção dos consumidores para a ativação das vendas, colocados em espaços separados dos demais tipos de FLV (grifo meu), incluindo produtos frescos;

- estratégia máxima fraca: refere-se a supermercados que oferecem mais de 51 itens orgânicos refrigerados no setor hortifruti, com mais de 10 marcas diferentes, predominantemente frescos e com exposição de destaque em refrigeradores. Mais do que isso, há uma preocupação do mercado com a qualidade e com a certificação dos 
produtos, além de ações permanentes de propaganda no ponto de venda, que departamentalizem a área dentro do setor, promovendo as vendas e facilitando o acesso por parte dos consumidores; sendo colocados em espaços exclusivos aos orgânicos, buscando a compartimentalização do setor (grifo meu);

- estratégia Máxima Forte: compromisso especial com os orgânicos, além de uma equipe treinada, motivada e educada, somada às outras características da "estratégia máxima fraca”.

\section{CONCLUSÃO}

Com o término da análise de produto, preço, propaganda e ponto de venda, acredita-se ser possível observar com maior clareza as semelhanças e distinções entre as estratégias desempenhadas pelos supermercados na venda de FLV orgânicos.

Na parte final da análise - descrita logo acima no final do item 2.4 - foram substituídos e incorporados os últimos elementos. Entretanto, desde o início da construção do modelo de análise (terceira parte), inúmeras modificações foram propostas, destaque para a substituição dos produtos em estoque e cadastrados por produtos na gôndola, a inserção de fatores relacionados à quantidade de marca, à quantidade e qualidade de comunicação e às análises qualitativas a respeito do ponto de venda.

Contudo, apesar dos novos atributos, acredita-se que a divisão entre estratégia mínima, básica e máxima (e suas graduações) ainda não é capaz de analisar adequadamente as especificidades do mercado nacional. Devido a estratégias heterogêneas, um determinado supermercado pode ainda ser inserido, por exemplo, na estratégia mínima forte com relação às marcas (com até 5) e na estratégia básica forte com relação a quantidade de itens (entre 31 e 50). Diante disso decidiu-se atribuir pontos a cada um dos elementos analisados e elaborar um novo método de classificação. Abaixo segue a tabela com a graduação das ações.

Os supermercados que somarem até 10 pontos são classificados como detentores de uma estratégia fraca, enquanto os que obtiverem de 


\begin{tabular}{|c|c|}
\hline Número de itens & Pontos \\
\hline Menos de 30 itens FLV orgânicos & 5 \\
\hline De 31 a 50 itens FLV orgânicos & 10 \\
\hline Mais de 51 itens FLV orgânicos & 20 \\
\hline Número de marcas & Pontos \\
\hline Menos de 5 marcas de FLV orgânicos & 5 \\
\hline De 6 a 10 marcas de FLV orgânicos & 10 \\
\hline Mais de 10 marcas de FLV orgânicos & 20 \\
\hline Comunicação & Pontos \\
\hline Sem nenhuma comunicação & 0 \\
\hline $\begin{array}{c}\text { Presença de ações a fím de atrair a } \\
\text { atenção para os produtos com intuito de } \\
\text { ativar as vendas }\end{array}$ & 10 \\
\hline $\begin{array}{l}\text { Presença de ações de ponto de venda } \\
\text { permanentes, que departamentalizem a } \\
\text { área dentro do setor, promovendo as } \\
\text { vendas e facilitando o acesso por parte } \\
\text { dos consumidores }\end{array}$ & 20 \\
\hline $\begin{array}{l}\text { Ponto de venda } \\
\end{array}$ & Pontos \\
\hline $\begin{array}{c}\text { Produtos orgânicos colocados misturados } \\
\text { com os convencionais, hidropônicos, } \\
\text { higienizados, etc. }\end{array}$ & 0 \\
\hline $\begin{array}{l}\text { Produtos orgânicos colocados separados } \\
\text { dos convencionais, hidropônicos, } \\
\text { higienizados, etc. }\end{array}$ & 10 \\
\hline $\begin{array}{c}\text { Produtos orgânicos colocados em espaços } \\
\text { exclusivos, buscando a } \\
\text { compartimentalização do setor }\end{array}$ & 20 \\
\hline
\end{tabular}

Tabela 1: Nova classificação das estratégias dos supermercados na venda de FLV orgânicos

11 a 30 pontos enquadram-se em uma estratégia denominada média/fraca. Já os supermercados que somarem de 31 a 50 pontos estão inseridos na estratégia média, enquanto uma pontuação entre 51 a 79 pontos evidencia uma estratégia média/forte. Por fim, os que obtiverem 80 pontos, ou seja, soma máxima em todos os itens, classificam-se como detentores de uma estratégia forte.

Através da somatória de pontos de cada supermercado pesquisado acreditase ser possível classificar as estratégias por eles desempenhadas, indo 
ao encontro da realidade do país. Mais do que isso, acredita-se que tal classificação possa ser aplicada também em pesquisas que visam comparar regiões, estados ou cidades no que concerne a venda de alimentos orgânicos por parte dos supermercados.

\section{REFERÊNCIAS}

ARAÚJO, C. A irresistível onda dos orgânicos. ISTO É DINHEIRO. Disponível em: http://www.terra.com.br/istoedinheiro/rural/capa07.htm

ARAÚJO, O. o Composto Mercadológico do Varejo. Disponível em: http://www. dearaujo.ecn.br/cgi-bin/asp/compostoMercadologicoVarejo.asp

CHAVES, A. F. Estudo das variáveis utilizadas na decisão de compras no comércio varejista de alimentos de auto-serviço - supermercados. 2002. Dissertação (mestrado). USP. Universidade de São Paulo, São Paulo

DUNNE, P. In: CZINKOTA, M. et al. Marketing: As melhores práticas. Porto Alegre: Bookman, 2001

GUIVANT, J. S. Supermarkets, organics and the ego-trip consumer. Paper presented at the Seminar on Organic Consumption: Kuala Lumpur, Malaysia, 2004.

GUIVANT, J. S. Os supermercados na oferta de alimentos orgânicos: apelando ao estilo de vida ego-trip. Ambiente \& sociedade. Campinas, Unicamp: v.VI, n.2, p.63-82, 2003.

KOTLER, P. Marketing. São Paulo: Atlas, 1980.

IBD. Agricultura Orgânica Conquista o mercado. Disponível em: http://www. ibd.com.br/News_Detalhe.aspx?idnews $=30$.

MORO, E. J. Estratégias desempenhadas pelo setor supermercadista na venda de alimentos orgânicos: estudo de caso em Florianópolis - SC. 2006. f.172. Monografia. Graduação em Ciências Sociais. UFSC. Universidade Federal de Santa Catarina, Florianópolis.

ORGANIC MONITOR. Disponível em http://www.organicmonitor.com/ 
ROCHA, A. da. CHRISTENSEN, C. Marketing: teoria e prática na Brasil. São Paulo: Altas, 1987

SILVA, A. T. Riscos Alimentares e Produtos Orgânicos: o papel dos supermercados na construção social dos consumidores de alimentos orgânicos em Florianópolis. 2003. Graduação em Ciências Sociais. UFSC. Universidade Federal de Santa Catarina, Florianópolis

SHIMP, T A. In: CZINKOTA, M. et al. Marketing: As melhores práticas. Porto Alegre: Bookman, 2001

URBANY, J. E. In: CZINKOTA, M. et al. Marketing: As melhores práticas. Porto Alegre: Bookman, 2001

U.S. DEPARTMENT OF AGRICUlTURE. The National Organic Program. Disponível em: http://www.ams.usda.gov/nop/indexIE.htm.

WILLER, H.; YUSSEFI, M..(eds) The World of Organic Agriculture 2007. Disponível em: http:/www.organic-world.net/2007.asp

WILLER, H.; YUSSEFI, M..(eds) The World of Organics Agriculture: Statistics and Emerging Trends 2005. Disponível em: http:/www.ifoam.org/press/press/ Statistics-2005.html. 